ASTHMA

\title{
Randomised, double blind, placebo-controlled trial of selenium supplementation in adult asthma
}

\author{
Seif O Shaheen, Roger B Newson, Margaret P Rayman, Angela P-L Wong, Michael K Tumilty, \\ Joanna M Phillips, James F Potts, Frank J Kelly, Patrick T White, Peter G J Burney
}

Thorax 2007;62:483-490. doi: 10.1136/thx.2006.071563

See end of article for authors' affiliations

Correspondence to: Dr Seif Shaheen, Respiratory Epidemiology and Public Health Group, NHLI at Imperial College London, Emmanuel Kaye Building, Manresa Road, London SW3 6LR, UK; s.shaheen@ imperial.ac.uk

Received 8 September 2006 Accepted 11 November 2006 Published Online First 17 January 2007

\begin{abstract}
Background: Epidemiological evidence from observational studies has suggested that blood levels and dietary intake of selenium of adults with asthma are lower than those of controls. The only previous trial of selenium supplementation in adults with asthma found no objective evidence of benefit but involved only 24 participants.

Methods: A randomised, double blind, placebo-controlled trial of selenium supplementation was performed in adults with asthma in London, UK, the majority of whom (75\%) reported inhaled steroid use at baseline. 197 participants were randomised to receive either a high-selenium yeast preparation (100 $\mu \mathrm{g}$ daily, $\mathrm{n}=99$ ) or placebo (yeast only, $\mathrm{n}=98$ ) for 24 weeks. The primary outcome was asthma-related quality of life (QoL) score. Secondary outcomes included lung function, asthma symptom scores, peak flow and bronchodilator usage. Linear regression was used to analyse the change in outcome between the two treatment arms by "intention to treat".

Results: There was a $48 \%$ increase in plasma selenium between baseline and end of trial in the active treatment group but no change in the placebo group. While the QoL score improved more in the active treatment group than in the placebo group, the difference in change in score between the two groups was not significant $(-0.05(95 \% \mathrm{Cl}-0.19$ to 0.09$) ; p=0.47)$. Selenium supplementation was not associated with any significant improvement in secondary outcomes compared with placebo.

Conclusions: Selenium supplementation had no clinical benefit in adults with asthma, the majority of whom were taking inhaled steroids.
\end{abstract}

( xidative stress has been suggested to play an important role in the pathogenesis of asthma, ${ }^{1}$ raising the possibility that dietary antioxidants, by contributing to antioxidant defences in the airways, might limit oxidative stress in the lungs and hence reduce asthma symptoms. A higher intake of selenium could plausibly suppress asthma inflammation by optimising the activity of antioxidant selenoenzymes such as glutathione peroxidase (GPx). This enzyme catalyses reduction of hydrogen peroxide, lipid and phospholipid hydroperoxides by the antioxidant glutathione in airway epithelial lining fluid. Glutathione is thought to play a role in defence against oxidative stress in asthmatic airways. ${ }^{2}$ Furthermore, selenium supplementation, by increasing GPx activity and decreasing oxidative stress, inhibits the activity of nuclear factor- $\kappa \mathrm{B}$, a key transcription factor driving the inflammatory process in asthma. ${ }^{34}$

It has been suggested that a falling dietary intake of antioxidants may have contributed to the rise in the prevalence of asthma in the UK. ${ }^{5}$ The antioxidant for which we have the clearest evidence of a marked decline in intake in recent decades in the UK is selenium. Intakes are much lower than in the USA and have fallen to levels which are about half of the UK Government's Reference Nutrient Intake (defined as the intake needed to maximise plasma GPx activity). ${ }^{6}$ Intakes in most parts of Europe are also considerably lower than in the USA. $^{7}$

Small hospital-based case-control studies in the UK, New Zealand and Australia have shown that blood levels of selenium and GPx activity were lower in adults with asthma than in controls, ${ }^{8-10}$ and there is also evidence for a positive crosssectional association between serum blood levels and dietary intake of selenium and adult lung function. ${ }^{11}$ Although one small study found no relation between dietary selenium intake and bronchial hyper-responsiveness in adults, ${ }^{12}$ in a larger population-based case-control study of adult asthma in London, UK we found that dietary intake was lower in cases than in controls. ${ }^{13}$

Despite the observational data implicating low blood levels and dietary intake of selenium in adult asthma, only one randomised controlled trial of selenium supplementation has been reported. ${ }^{14}{ }^{15}$ In that study, participants were randomised to receive either $100 \mu \mathrm{g}$ sodium selenite or placebo. The authors reported improvement based on a composite clinical evaluation, but there was no improvement in individual objective measures such as lung function and bronchial hyper-responsiveness. ${ }^{15}$ However, this trial had a number of limitations. It was very small (only 12 participants in each arm) and therefore lacked statistical power to detect modest effects; only adults with nonatopic asthma were included, which may have limited the generalisability of the findings; and the duration of the trial was only 14 weeks, which may have been too short to achieve maximum benefit. We therefore carried out a much larger randomised controlled trial of selenium supplementation of longer duration in adults with asthma living in London to determine whether supplementation led to improvements in asthma-related quality of life and other measures of asthma severity. While observational studies have demonstrated links between selenium levels and the prevalence of asthma, and data are lacking on selenium and asthma severity, we reasoned that selenium might influence the prevalence of asthma by preventing subclinical disease from manifesting as mild clinical

Abbreviations: COPD, chronic obstructive pulmonary disease; FEF, forced expiratory flow; $\mathrm{FEV}_{1}$, forced expiratory volume in $1 \mathrm{~s} ; \mathrm{FVC}$, forced vital capacity; GPx, glutathione peroxidase; PEF, peak expiratory flow; QoL, quality of life; RBC, red blood cell; SELINA, SELenium IN Asthma 
disease. Thus, supplementation in mild to moderate asthma might shift individuals from moderate to mild and from mild to subclinical disease.

\section{METHODS}

The study was a randomised, double blind, placebo controlled trial (parallel group) and is registered as an International Standard Randomised Controlled Trial number ISRCTN31432640. Ethics approval was obtained from the Greenwich and Guy's research ethics committees. Participants gave informed written consent.

\section{Participants}

Initially we identified potential participants from among adults with asthma (defined by positive responses to questions about asthma attacks in the last 12 months or current asthma treatment) who had taken part either in a case-control study of diet and asthma in the London borough of Greenwich 5 years previously, then aged $16-50$ years, ${ }^{13}$ or in a more recent survey of respiratory symptoms in adults aged 18-54 in the London boroughs of Lambeth, Southwark and Lewisham. These population-based studies involved adults identified from the registers of general practitioners in these areas. As inadequate numbers of potential participants could be recruited in this way, we amended our protocol to use other methods of recruitment. A few additional potential participants were found through advertisements in local papers and by email circulated at King's College London, but most potential participants were found through 12 general practices in the London boroughs of Lambeth, Southwark and Lewisham by identifying all patients aged 18-54 who had received a prescription for inhaled corticosteroids in the previous 6 months.

Potential participants were screened to confirm that they had had asthma symptoms in the last month and were not taking a supplement containing selenium. 849 respondents who fulfilled these initial inclusion criteria were assessed further for eligibility and were excluded if they could not give informed consent, could not swallow tablets, were or intended to become pregnant or were lactating, had a history of renal or liver disease, suffered from yeast intolerance or could not perform spirometric tests satisfactorily.

\section{Treatments}

Eligible participants were given placebo treatment containing yeast (one tablet daily) for a 3 week "run-in" period. Those who suffered gastrointestinal side effects or took fewer than $80 \%$ of the tablets (missed treatment on more than 4 days out of 21) were excluded from the main trial. The treatment arm (selenium or placebo) was determined by randomisation within blocks of four consecutive participants. Computer-generated random numbers were used to randomise treatments but the allocation of treatments was concealed from the investigators and the codes were not broken until the trial was completed. The treatment suppliers made up two 3-month blister treatment packs, distinguished only by participant number.

Participants enrolled into the main trial were assigned either a yeast preparation of selenium (SelenoPrecise, Pharma Nord, Denmark; $100 \mu \mathrm{g}$ daily) or placebo (yeast only) for 24 weeks. Active and placebo tablets were indistinguishable in appearance, taste and smell. Unused pills were returned at mid-trial and end of trial and counted. Participants were monitored for adverse events and side effects related to selenium toxicity such as nail splitting and hair loss.

\section{Clinical assessments and outcomes}

Assessments were carried out at baseline and end of trial between May 2002 and May 2005. Participants who dropped out were encouraged to provide outcome measurements at 24 weeks. At baseline, information was collected on sociodemographic characteristics, risk factors for asthma, medications and non-selenium dietary supplements.

Lung function was measured using a portable spirometer (Vitalograph 2120, Vitalograph Ltd, UK) according to ATS guidelines. The highest values of forced expiratory volume in l s $\left(\mathrm{FEV}_{1}\right)$ and forced vital capacity (FVC) and the value of forced expiratory flow $\left(\mathrm{FEF}_{25-75}\right)$ from the "ATS best test" were used in the analyses. ${ }^{16} \mathrm{FEV}_{1} \%$ predicted was calculated using prediction equations for the English population. ${ }^{17}$ Participants were asked to avoid taking bronchodilators for $4 \mathrm{~h}$ before the test ( $8 \mathrm{~h}$ for long-acting bronchodilators). As far as possible, end of trial lung function was measured at a similar time of day as the baseline assessment.

Asthma-related quality of life was measured using the Marks Asthma Quality of Life (QoL) instrument. ${ }^{18}$ This instrument has been used successfully in this population, has been validated against objective measures of asthma severity, ${ }^{19} 20$ and has been shown to be sensitive to change over periods of 3 weeks ${ }^{21}$ and 4 months. $^{20}$ A QoL score was derived from Likert scale responses (0-4) to 20 questions about the impact of asthma on activities and quality of life in the previous 4 weeks. A higher score (out of 10) indicates a worse quality of life. To define mild exacerbations, ${ }^{22}$ participants were asked whether, in the previous 4 weeks, there had been two or more consecutive days when they had had to use their bronchodilator four or more times in addition to their usual usage in $24 \mathrm{~h}$ because their asthma/breathing had got worse; and whether they had been woken at night because of asthma/breathing problems on two or more consecutive nights.

For 14 days before the main assessments, participants were asked to record their morning and evening prebronchodilator peak expiratory flow (PEF) using an electronic peak flow meter (One Flow, Clement-Clarke International, UK). This stored the best of three blows with the time and date. We calculated a mean value for best morning PEF and for PEF variability, measured as amplitude \% mean $(100 \times(\max -\min ) /$ mean $)$ for each day of readings, then averaged over the number of days. Participants recorded nocturnal and daytime severity of asthma symptoms (0-4, higher being worse) in a diary the following morning and evening, respectively, allowing calculation of mean morning and evening scores. They also recorded their asthma drug usage daily, enabling calculation of mean daily short-acting inhaled bronchodilator usage. We excluded PEF data on days when there were not two sets of readings. Individuals who had recorded PEF or diary data (symptoms and drug use) for less than 7 days in total (these did not have to be consecutive days) were regarded as having "missing" data for these outcomes. PEF and symptom data for three individuals who worked night shifts were also regarded as "missing".

Plasma selenium and vitamin E and red cell GPx levels were measured in blood samples from those willing to give them (see supplementary Methods available online at http://thorax.bmj.com/supplemental).

The primary outcome was asthma-related QoL score (square root transformed, as in previous studies). Secondary outcomes included $\mathrm{FEV}_{1}, \mathrm{FEV}_{1} / \mathrm{FVC}, \mathrm{FEF}_{25-75}, \mathrm{FEF}_{25-75} / \mathrm{FVC}$ (associated with bronchial hyper-responsiveness ${ }^{23}$ ), mean morning $\mathrm{PEF}$, PEF variability, mean morning and evening asthma symptom scores, waking at night with asthma, increased bronchodilator use and mean bronchodilator usage.

\section{Sample size estimation}

Assuming a standard deviation for the change in square root transformed QoL score of $0.55,{ }^{24}$ we estimated that 100 


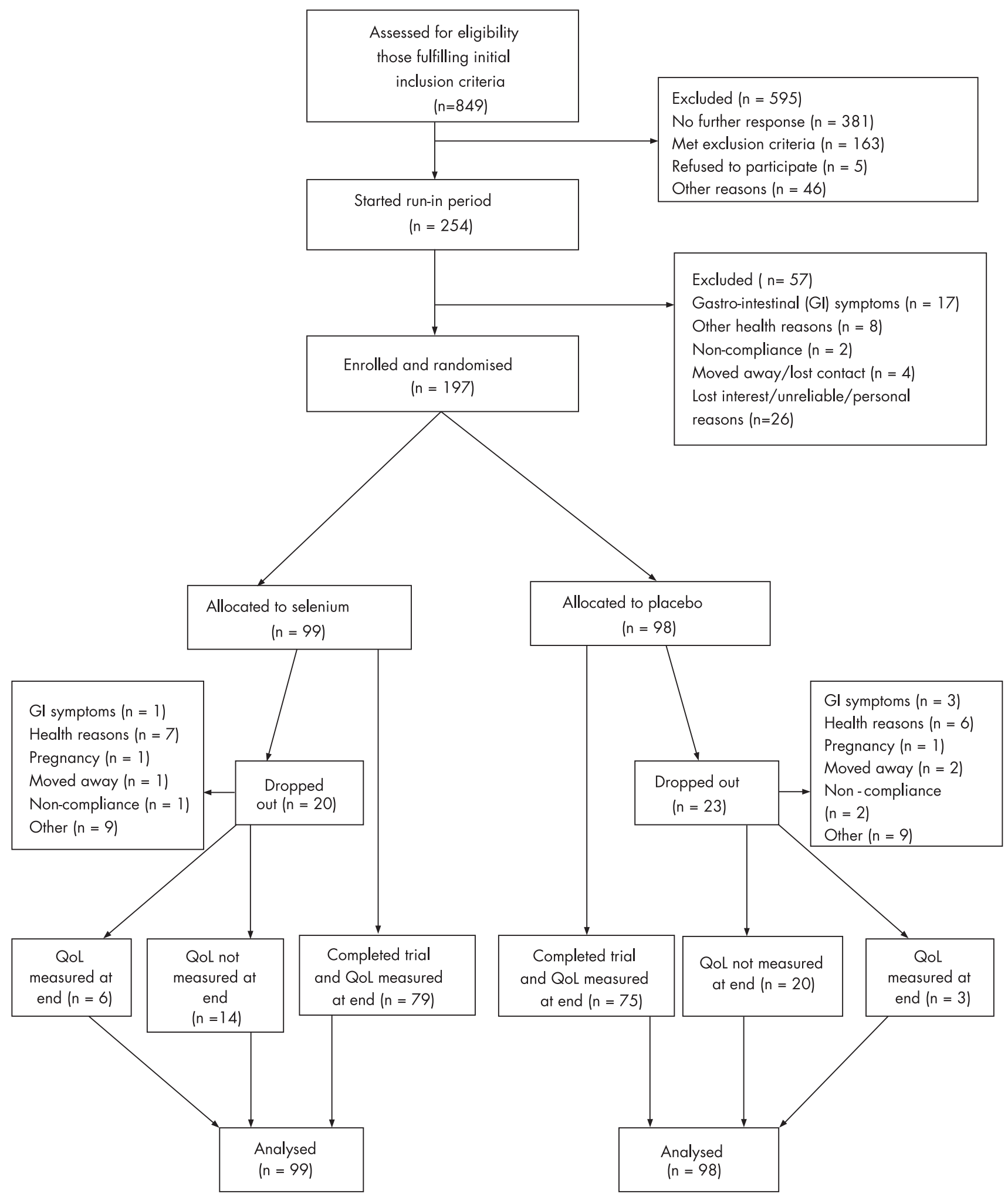

Figure 1 Trial profile. QoL, quality of life.

participants in each treatment arm would give $80 \%$ power at the $5 \%$ significance level to detect a mean difference in the change in transformed QoL score between baseline and end of trial of 0.22 between active and placebo treatments. (In our case-control study we found that a doubling of selenium intake in cases in the bottom quintile for selenium was associated with a reduction in transformed score of 0.32 ; this compares with a reduction of $0.31-0.42$ in a trial of high-dose inhaled steroids ${ }^{24}$ ). Assuming a SD for within-group change in $\mathrm{FEV}_{1}$ of 0.41 litres, ${ }^{25}$ we estimated that 100 participants in each arm would give $80 \%$ 
Table 1 Distribution of sociodemographic and clinical characteristics at baseline in randomised individuals according to treatment arm

\begin{tabular}{|c|c|c|c|c|}
\hline & \multicolumn{2}{|c|}{ Placebo } & \multicolumn{2}{|c|}{ Selenium } \\
\hline & $\mathbf{N}$ & $\%$ & $\mathbf{N}$ & $\%$ \\
\hline Male & 98 & 44.90 & 99 & 30.30 \\
\hline Current cigarette smoker & 98 & 30.61 & 99 & 30.30 \\
\hline Rhinitis symptoms & 98 & 64.29 & 99 & 63.64 \\
\hline Housing owned/mortgaged & 98 & 50.00 & 99 & 55.56 \\
\hline Prescribed inhaled steroids & 98 & 92.86 & 99 & 92.93 \\
\hline Taking inhaled steroids & 95 & 75.79 & 96 & 73.96 \\
\hline Taking oral steroids & 95 & 3.16 & 96 & 1.04 \\
\hline \multirow[t]{2}{*}{ Taking non-selenium supplements } & 98 & 28.57 & 99 & 32.32 \\
\hline & $\mathbf{N}$ & $\begin{array}{l}\text { Arithmetic } \\
\text { mean }\end{array}$ & $\mathbf{N}$ & $\begin{array}{l}\text { Arithmetic } \\
\text { mean }\end{array}$ \\
\hline Age (years) & 98 & 40.73 & 99 & 40.00 \\
\hline $\mathrm{BMI}\left(\mathrm{kg} / \mathrm{m}^{2}\right)$ & 98 & 28.44 & 99 & 28.50 \\
\hline QoL score (square root transformed) & 98 & 1.46 & 99 & 1.39 \\
\hline $\mathrm{FEV}_{1}$ (I) & 98 & 2.64 & 99 & 2.66 \\
\hline $\mathrm{FEV}_{1}(\%$ predicted $)$ & 98 & 76.67 & 99 & 79.70 \\
\hline Daytime asthma symptom score & 90 & 1.08 & 95 & 0.85 \\
\hline Night-time asthma symptom score & 92 & 0.92 & 95 & 0.76 \\
\hline Morning PEF (I/min) & 79 & 369.41 & 85 & 383.95 \\
\hline Bronchodilator dose (puffs/day) & 95 & 2.82 & 96 & 2.26 \\
\hline
\end{tabular}

power at the $5 \%$ significance level to detect a mean difference in the change in $\mathrm{FEV}_{1}$ between baseline and end of trial of 0.16 litres between active and placebo treatments, which we would regard as clinically important.

\section{Statistical methods}

In the primary analyses we analysed 6 month outcomes by "intention to treat". Among the participants who dropped out, outcome data at 24 weeks were available for some individuals. Data on secondary outcomes, especially symptom scores and peak flows, were incomplete for some individuals who completed the trial. We therefore corrected for missing outcome data using sampling probability weighting (see supplementary Methods available online at http://thorax.bmj.com/supplemental).

In secondary analyses we repeated these analyses, controlling for chance imbalance in potential confounders at baseline (using a propensity score for the event of allocation to selenium treatment), and carried out an unweighted analysis restricted to individuals with complete measured outcome data. (Substraction of " $\mathrm{n}$ " in the unweighted analyses (see supplementary tables online at http://thorax.bmj.com/supplemental) from " $\mathrm{n}$ " in the main weighted analyses will clarify, for each outcome, the amount of missing data which had to be corrected for, using sampling probability weighting in the main analyses).

We also carried out some planned subgroup analyses: (1) we stratified the analyses by tertile of baseline plasma selenium among the 145 individuals who had given blood samples to see if the effects of supplementation were greatest in those with the lowest selenium status; (2) we stratified above and below the median level of baseline plasma $\alpha$-tocopherol as selenium and vitamin $\mathrm{E}$ are thought to act synergistically; ${ }^{26}$ and (3) we excluded $10 \%$ of individuals who had an untransformed QoL score $\leqslant 0.625$ (equivalent to giving a response to 5 questions about how asthma was affecting them of "mildly" and to the remaining 15 questions of "not at all"), as they had little scope for improvement in QoL. Post hoc, we also stratified by baseline smoking status (current, yes/no), non-selenium supplement use (yes/no), use of inhaled steroids at baseline (yes/no), and by severity of asthma as defined by $\mathrm{FEV}_{1} \%$ predicted $(<80 \%$ vs $\geqslant 80 \%$ ).

To compare outcomes between treatment arms, logistic regression was used to compare odds for binary outcomes (end of trial measures), linear regression on logs to compare geometric means for PEF variability (log end of trial/baseline ratios), and linear regression to compare arithmetic means for

Table 2 Plasma selenium, red blood cell (RBC) glutathione peroxidase and plasma $\alpha$ - and $\gamma$ tocopherol measurements at baseline and end of trial in those from whom blood samples were obtained, according to treatment arm

\begin{tabular}{|c|c|c|c|c|}
\hline & \multicolumn{2}{|c|}{ Placebo } & \multicolumn{2}{|c|}{ Selenium } \\
\hline & $\mathbf{N}$ & $\begin{array}{l}\text { Geometric } \\
\text { mean }\end{array}$ & $\mathbf{N}$ & $\begin{array}{l}\text { Geometric } \\
\text { mean }\end{array}$ \\
\hline Plasma selenium $(\mu \mathrm{g} / \mathrm{l})$ at baseline & 73 & 84.05 & 72 & 81.54 \\
\hline Plasma selenium $(\mu \mathrm{g} / \mathrm{l})$ at end & 57 & 81.99 & 46 & 121.02 \\
\hline $\mathrm{RBC}$ glutathione peroxidase (units/mg $\mathrm{Hb}$ ) at baseline & 73 & 28.88 & 72 & 28.12 \\
\hline $\mathrm{RBC}$ glutathione peroxidase (units/mg $\mathrm{Hb}$ ) at end & 56 & 28.53 & 46 & 29.15 \\
\hline Plasma $\alpha$-tocopherol (mmol/mol cholesterol) at baseline & 72 & 5.91 & 67 & 5.61 \\
\hline Plasma $\alpha$-tocopherol $(\mathrm{mmol} / \mathrm{mol}$ cholesterol) at end & 55 & 5.52 & 46 & 5.62 \\
\hline Plasma $\gamma$-tocopherol $(\mathrm{mmol} / \mathrm{mol}$ cholesterol) at baseline & 72 & 0.29 & 67 & 0.30 \\
\hline Plasma $\gamma$-tocopherol $(\mathrm{mmol} / \mathrm{mol}$ cholesterol) at end & 55 & 0.27 & 46 & 0.26 \\
\hline
\end{tabular}


Table 3 Arithmetic mean differences in asthma severity outcomes (end of trial minus baseline)

\begin{tabular}{|c|c|c|c|}
\hline Outcome & $\mathrm{N}$ & Difference $(95 \% \mathrm{Cl})$ & p Value \\
\hline \multicolumn{4}{|l|}{ Square root QoL score } \\
\hline Placebo & 98 & $-0.17(-0.27$ to -0.06$)$ & 0.0025 \\
\hline Selenium & 99 & $-0.22(-0.31$ to -0.13$)$ & $4.0 \times 10^{-6}$ \\
\hline Selenium-placebo difference & 197 & $-0.05(-0.19$ to 0.09$)$ & 0.47 \\
\hline \multicolumn{4}{|c|}{ Mean night-time asthma symptom score } \\
\hline Placebo & 98 & $-0.18(-0.36$ to 0.01$)$ & 0.057 \\
\hline Selenium & 99 & $-0.14(-0.30$ to 0.01$)$ & 0.067 \\
\hline Selenium-placebo difference & 197 & $0.04(-0.21$ to 0.28$)$ & 0.77 \\
\hline \multicolumn{4}{|c|}{ Mean daytime asthma symptom score } \\
\hline Placebo & 98 & $-0.15(-0.34$ to 0.04$)$ & 0.13 \\
\hline Selenium & 99 & $-0.12(-0.29$ to 0.05$)$ & 0.17 \\
\hline Selenium-placebo difference & 197 & $0.03(-0.23$ to 0.29$)$ & 0.83 \\
\hline \multicolumn{4}{|c|}{ Mean bronchodilator dosage (puffs/day) } \\
\hline Placebo & 98 & $-0.60(-1.23$ to 0.02$)$ & 0.058 \\
\hline Selenium & 99 & $-0.92(-1.67$ to -0.17$)$ & 0.017 \\
\hline Selenium-placebo difference & 197 & $-0.32(-1.29$ to 0.66$)$ & 0.52 \\
\hline
\end{tabular}

other continuous outcomes (end of trial minus baseline differences), using Huber variances and Stata V.9.0.

\section{RESULTS}

Figure 1 shows the trial profile and completeness of primary outcome data. Of 254 individuals who began the run-in period, 197 were enrolled and randomised, and allocation of treatments was balanced. Of 157 individuals for whom data on tablet counts were available, 78/80 taking placebo and 75/77 taking selenium had taken $80 \%$ or more of the treatment supplied over 24 weeks. Participants who dropped out $(n=43)$ did so before or at mid-trial, and the proportion of drop-outs from the two treatment arms was similar. There were no serious adverse events or side effects in either treatment group. During the run-in period and during the main trial some individuals dropped out because of gastrointestinal symptoms which may have been related to yeast intolerance.

Table 1 shows the sociodemographic and clinical characteristics at baseline in the 197 randomised individuals according to treatment arm. With the exception of sex, the distribution of all variables at baseline was very similar in the active treatment and placebo groups. While $93 \%$ of participants had been prescribed inhaled steroids, only $75 \%$ reported taking them. Overall, $52 \%$ of participants had an $\mathrm{FEV}_{1} \%$ predicted $<80 \%$. The median plasma selenium level in all participants with data at baseline was $81.3 \mu \mathrm{g} / \mathrm{l}$ (95\% CI 78.8 to 85.4 ).

Table 2 shows plasma selenium and vitamin E levels and red blood cell (RBC) GPx measurements at baseline and end of trial, according to treatment arm. There was a $48 \%$ increase in plasma selenium between baseline and end of trial in the active treatment group, but no change in the placebo group. However, there was only a very small increase in RBC GPx activity between baseline and end of trial in the active treatment group. $\alpha$ - and $\gamma$-tocopherol concentrations did not change in either group.

At baseline, $97 \%$ and $90 \%$ of participants achieved a difference between the highest and second highest $\mathrm{FEV}_{1}$ and FVC of $\leqslant 0.2$ litres, respectively. ${ }^{16}$ Tables $3-6$ show the results of the main weighted analyses of primary and secondary outcomes. While some indicators of asthma severity improved more in individuals receiving selenium than in those receiving placebo (QoL score, mean bronchodilator use, additional bronchodilator use, waking at night and morning peak flow), this was not the case for other outcomes including asthma symptom scores and lung function. Furthermore, all differences were small and not significant.

These results were very similar when we repeated the analyses controlling for potential confounders at baseline (data not shown), and when we restricted the analysis of each outcome to individuals with complete measured outcome data ( see supplementary tables El-E4 online at http://thorax.bmj. com/supplemental/).

In planned stratified analyses, no statistically significant effects of selenium treatment were found on any outcome in individuals in the bottom tertile of baseline plasma selenium (range $55.5-76.3 \mu \mathrm{g} / \mathrm{l}$ ) or in those with plasma $\alpha$-tocopherol levels below the median, nor when individuals with very mild asthma (as defined by QoL score) were excluded (data not shown). In post hoc stratified analyses, no statistically significant effects were found in smokers or non-smokers, in those not taking non-selenium supplements or inhaled steroids at baseline, or when stratified by $\mathrm{FEV}_{1} \%$ predicted (data not shown). Unexpectedly, in individuals who were in the highest tertile for selenium at baseline or were taking non-selenium supplements, selenium was associated with a higher night-time asthma symptom score (difference in mean score 0.41 (95\% CI

Table 4 Odds and odds ratios for additional bronchodilator use and waking at night with asthma symptoms at end of trial

\begin{tabular}{lrll}
\hline Outcome & N & Odds/OR (95\% Cl) & p Value \\
\hline Additional bronchodilator usage & 98 & $0.37(0.22$ to 0.62$)$ & \\
$\quad \begin{array}{l}\text { Placebo } \\
\text { Selenium }\end{array}$ & 99 & $0.22(0.13$ to 0.39$)$ & 0.00017 \\
$\quad$ Selenium/placebo ratio & 197 & $0.61(0.28$ to 1.30$)$ & $1.6 \times 10^{-7}$ \\
Woken at night with asthma symptoms & & & 0.2 \\
$\quad \begin{array}{l}\text { Placebo } \\
\text { Selenium }\end{array}$ & 98 & $0.39(0.23$ to 0.64$)$ & 0.00021 \\
Selenium/placebo ratio & 99 & $0.33(0.20$ to 0.55$)$ & 0.000013 \\
\end{tabular}


Table 5 Arithmetic mean differences in lung function (end of trial minus baseline)

\begin{tabular}{|c|c|c|c|}
\hline Outcome & N & Difference $(95 \% \mathrm{Cl})$ & $p$ Value \\
\hline \multicolumn{4}{|l|}{$\mathrm{FEV}_{1}$ (l) } \\
\hline Placebo & 98 & $-0.05(-0.10$ to 0.01$)$ & 0.089 \\
\hline Selenium & 99 & $-0.04(-0.11$ to 0.04$)$ & 0.36 \\
\hline Selenium-placebo difference & 197 & $0.01(-0.08$ to 0.10$)$ & 0.81 \\
\hline \multicolumn{4}{|l|}{$\mathrm{FEF}_{25-75}(\mathrm{l} / \mathrm{s})$} \\
\hline Placebo & 98 & $-0.02(-0.15$ to 0.10$)$ & 0.73 \\
\hline Selenium & 99 & $-0.03(-0.14$ to 0.08$)$ & 0.59 \\
\hline Selenium-placebo difference & 197 & $-0.01(-0.18$ to 0.16$)$ & 0.92 \\
\hline \multicolumn{4}{|l|}{$\mathrm{FEV}_{1} / \mathrm{FVC}$ ratio } \\
\hline Placebo & 98 & $0.01(-0.01$ to 0.02$)$ & 0.55 \\
\hline Selenium & 99 & $-0.00(-0.01$ to 0.01$)$ & 0.95 \\
\hline Selenium-placebo difference & 197 & $-0.01(-0.03$ to 0.01$)$ & 0.58 \\
\hline \multicolumn{4}{|l|}{$\mathrm{FEF}_{25-75} / \mathrm{FVC}$ ratio } \\
\hline Placebo & 98 & $0.01(-0.03$ to 0.05$)$ & 0.67 \\
\hline Selenium & 99 & $-0.00(-0.03$ to 0.03$)$ & 0.9 \\
\hline Selenium-placebo difference & 197 & $-0.01(-0.06$ to 0.04$)$ & 0.68 \\
\hline
\end{tabular}

0.14 to 0.67 ), $\mathrm{p}=0.0033$, and 0.54 (95\% CI 0.19 to 0.90 ), $\mathrm{p}=0.0038$, respectively).

\section{DISCUSSION}

In this randomised controlled trial we found no clinical benefit of selenium supplementation in adults with asthma taking inhaled steroids. These negative findings are of interest because, despite a body of observational data implicating low selenium levels in asthma, no supplementation trial of adequate size has previously been carried out. While smokers were not excluded from the trial, the upper age limit of participants was 54 years, making it less likely that they had misdiagnosed smoking-related symptoms or chronic obstructive pulmonary disease (COPD) rather than asthma. Even if the phenotype did differ between smokers and non-smokers, one might expect benefits of selenium supplementation in smokers too, given that lower selenium levels have been linked to lower lung function, especially in smokers. ${ }^{11}$ We stratified our analyses by smoking status for a number of reasons. On the one hand, if selenium was more beneficial for asthma than for early COPD, then one might expect to see stronger effects among non-smokers. On the other hand, greater benefits of selenium might be predicted among smokers, either because they have a higher level of oxidative stress or because inhaled steroids, which could potentially mask any beneficial effect of selenium, are ineffective in smokers with mild asthma. ${ }^{27}$ The results, however, were no different between smokers and nonsmokers.

\section{Strengths of the study}

The similar distribution of background characteristics and blood variables at baseline between treatment arms suggests that randomisation was effective. The lower proportion of men in the active treatment group is likely to have arisen by chance. Our trial was substantially larger and of longer duration than the only previous selenium supplementation trial. ${ }^{15}$ We aimed to have 200 participants completing this trial, after allowing for drop-outs. While we randomised almost 200 individuals, 43 of these did not complete the trial and their inclusion in the intention-to-treat analysis of the primary outcome may have diluted any beneficial effects of selenium compared with placebo. However, the confidence intervals for the QoL score and $\mathrm{FEV}_{1}$ effect estimates suggest that the study has excluded beneficial effects of 0.22 in transformed score and 0.16 litres, respectively, as specified in our sample size calculation. Thus, if supplementation is beneficial for asthma, the effects are likely to be smaller and of little clinical significance. Our choice of asthma-related quality of life as the primary outcome was influenced by the observation that clinically important improvements in QoL have been demonstrated previously using a similar instrument when other clinical outcomes more commonly used in asthma treatment trials have not improved. ${ }^{28}$

As the trial was performed in the same locality where a relation between low dietary intake of selenium and asthma was previously found, we hoped to optimise the chance of detecting any beneficial effect of selenium supplementation. Given that we recruited predominantly through primary care and that baseline selenium status was similar to that of a national sample (see below), we believe that our findings can be generalised to the UK population of adults with mild to moderate asthma. The substantial increase in plasma selenium in the active treatment group, but not in the placebo arm, and the pill count data suggest that poor compliance is unlikely to explain the negative results. The dose and form of selenium and duration of treatment were chosen with careful reference to the published literature. ${ }^{29}{ }^{30} \mathrm{We}$ chose a selenium-yeast preparation

Table 6 Arithmetic mean differences in morning peak expiratory flow (PEF, end of trial minus baseline) and geometric mean end of trial/baseline ratios for PEF variability

\begin{tabular}{lrcl}
\hline Outcome & N & Difference/GM ratio (95\% CI) & p Value \\
\hline Mean morning PEF (I/min) & 98 & $-2.25(-15.01$ to 10.52$)$ & 0.73 \\
$\quad$ Placebo & 99 & $5.19(-9.40$ to 19.79$)$ & 0.48 \\
$\quad$ Selenium & 197 & $7.44(-11.95$ to 26.83$)$ & 0.45 \\
$\quad$ Selenium-placebo difference & & & \\
Mean PEF amplitude (\% mean) & 98 & $0.97(0.88$ to 1.08$)$ & 0.62 \\
$\quad$ Placebo & 99 & $0.92(0.82$ to 1.04$)$ & 0.19 \\
$\quad$ Selenium & 197 & $0.95(0.81$ to 1.11$)$ & 0.52 \\
Selenium/placebo ratio & & & \\
\hline
\end{tabular}


in preference to sodium selenite (used in the previous supplementation trial $^{15}$ ) because of its greater similarity to selenium in food sources ${ }^{30}$ and its high content of selenomethionine which is much more bioavailable than inorganic selenium. ${ }^{29}$ Similarly, we reasoned that a daily dose of $100 \mu \mathrm{g}$ selenium, added to the likely background intake of 30-40 $\mu \mathrm{g}$ selenium/day, ${ }^{31-33}$ would be sufficient to optimise the activity and concentration of all the selenoproteins ${ }^{29}$ and that treatment for 24 weeks would be sufficient for selenoenzyme activity to plateau $^{34}$ and translate into potential reductions in airway inflammation and symptomatic improvement. We think it unlikely that our results would have been different with a higher supplement dose given for a longer period.

\section{Possible explanations for negative results}

Given the above, there are a number of possible explanations for the negative findings. First, there may be no causal link between selenium and asthma. Negative associations between dietary selenium intake ${ }^{13}$ or blood selenium ${ }^{8-10}$ and prevalence of adult asthma have come from cross-sectional studies and may have arisen through bias or uncontrolled confounding. The latter may also explain why protective associations between antioxidant vitamins and adult asthma suggested by observational studies have not been confirmed in recent supplementation trials, ${ }^{35}{ }^{36}$ a disparity also seen for antioxidant vitamins in relation to cardiovascular disease and cancer. ${ }^{37}$

Second, we may be intervening too late in the natural history. We previously considered whether the apparent association between the prevalence of asthma and selenium intake in adults might actually reflect an effect of selenium intake in childhood on the inception of asthma, ${ }^{13}$ especially since lower serum selenium levels have been shown to predict later wheezing in children. ${ }^{38}$ This has also been put forward as an alternative explanation for the disappointing results of antioxidant vitamin trials in adult asthma. ${ }^{39}$ However, we now doubt this explanation. Nutrient intake has been shown to "track" in early childhood, with one study reporting that a high proportion of children in the highest or lowest quintile of intake at 3-4 years of age were in the same quintile at 7-8 years of age. ${ }^{40}$ However, another study found that nutrient intake in adolescence is not a good predictor of adult nutrient intake, ${ }^{41}$ suggesting that intakes in early childhood are unlikely to be highly correlated with intakes in adulthood.

Third, selenium might be beneficial in severe asthma but not in mild asthma. Our participants were recruited from the community, so the majority had mild to moderate disease. We found no evidence, however, to suggest a stronger effect of selenium when individuals with a very low QoL score or those with an $\mathrm{FEV}_{1}<80 \%$ predicted were excluded.

Fourth, clinical benefit may only be derived when selenium levels are lower than in our studied population. The median plasma selenium level of our trial participants at baseline was similar to that of men and women of a similar age in the recent UK National Diet and Nutrition Survey. ${ }^{42}$ This value is arguably sufficient for near-optimal activity of plasma GPx ${ }^{43}$ which has been shown to require a plasma concentration of approximately $90 \mu \mathrm{g} / \mathrm{l}^{44}$ Thus, for a substantial proportion of our trial participants, little benefit may have been derived from selenium supplementation because their selenium status at baseline was adequate for plasma GPx expression. This supposition is substantiated by the finding that there was only a marginal increase in overall RBC GPx activity after 24 weeks in the active treatment group, despite the replacement of all the red blood cells (lifespan 120 days) over the course of the trial. Although our study was not powered to detect significant effects in small subgroups of individuals with blood data and confidence intervals around the effect estimates were wide, we found no evidence of a beneficial effect, even for individuals in the bottom tertile of plasma selenium.

Finally, the benefits of selenium supplementation might have been limited by the fact that most of the study participants were using inhaled steroids, which will have been suppressing airway inflammation and oxidative stress in those taking them regularly. While we did not find evidence for a statistically significant beneficial effect of selenium in those not taking inhaled steroids at baseline, the statistical power was limited in this small group. With hindsight, it would have been of interest to see whether supplementation could have facilitated greater controlled reduction in steroid dosage in the active treatment group compared with the placebo group.

In conclusion, this randomised clinical trial suggests that, in the UK where the selenium status of the population is lower than in many other countries, the empirical use of selenium supplementation as an adjunct to conventional treatment is unlikely to be a useful public health strategy for the secondary prevention of mild to moderate adult asthma. We cannot rule out the possibility, however, that selenium supplementation might be beneficial in children, in adults with severe asthma and in those with lower selenium levels than in our studied population.

\section{ACKNOWLEDGEMENTS}

The authors thank all the trial participants, Sven Moesgaard (Research Director, Pharma Nord) who supplied the trial treatment packs, Christine Sieniawska (Trace Element Unit, Southampton General Hospital) who measured the plasma selenium samples, Chrissi Dunster (KCL) who measured vitamin E and GPx, Professor Swaminathan (Guy's Chemical Pathology department) for cholesterol measurement, and Professor Doug Altman for advice on analysis of missing data

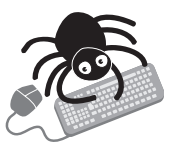

Further data are available online at http:// thorax.bmj.com/supplemental.

\section{Authors' affiliations \\ Seif O Shaheen, Roger B Newson, Angela P-L Wong, Michael K Tumilty, Joanna M Phillips, James F Potts, Peter G J Burney, Respiratory \\ Epidemiology and Public Health Group, National Heart and Lung Institute (NHLI) at Imperial College London, London, UK \\ Margaret P Rayman, Division of Nutrition, Dietetics and Food Science, School of Biomedical and Life Sciences, University of Surrey, Guildford, Surrey, UK \\ Frank J Kelly, Pharmaceutical Sciences Research Division, School of Biomedical and Health Sciences, King's College London \\ Patrick T White, Department of General Practice and Primary Care, King's College London, UK}

This study was carried out as part of the research programme funded by the Department of Health's Policy Research Programme. SOS is an Asthma UK Senior Research Fellow.

Competing interests: None.

SS, PB and MR conceived and designed the study; SS supervised and had overall clinical responsibility for the project and drafted the manuscript; JP coordinated the project and was responsible for project documentation; AW and MT carried out all the fieldwork; RN carried out the power calculations and statistical analyses; MR gave advice on selenium measurement and supplementation; FK supervised measurement of vitamin $\mathrm{E}$ and GPx; PW gave advice regarding recruitment of participants through local general practices; JP assisted with data management; all authors revised or commented on the draft manuscript.

\section{REFERENCES}

1 Barnes PJ. Reactive oxygen species and airway inflammation. Free Radic Biol Med 1990;9:235-43. 
2 Kelly FJ, Mudway I, Blomberg A, et al. Altered lung antioxidant status in patients with mild asthma. Lancet 1999;354:482-3.

3 Sappey C, Legrand-Poels S, Best-Belpomme M, et al. Stimulation of glutathione peroxidase activity decreases HIV type 1 activation after oxidative stress. AIDS Res Hum Retrovir 1994;10:1451-61.

4 Jeong DW, Yoo MH, Kim TS, et al. Protection of mice from allergen-induced asthma by selenite: prevention of eosinophil infiltration by inhibition of NF-kappa B activation. J Biol Chem 2002;277:17871-6.

5 Seaton A, Godden DJ, Brown K. Increase in asthma: a more toxic environment or a more susceptible population? Thorax 1994;49:171-4.

6 Rayman MP. Dietary selenium: time to act. BMJ 1997;314:387-8.

7 Rayman MP. The importance of selenium to human health. Lancet 2000;356:233-41.

8 Stone J, Hinks $\amalg$, Beasley R, et al. Reduced selenium status of patients with asthma. Clin Sci 1989;77:495-500.

9 Flatt $A$, Pearce N, Thomson CD, et al. Reduced selenium in asthmatic subjects in New Zealand. Thorax 1990;45:95-9.

10 Misso NL, Powers KA, Gillon RL, et al. Reduced platelet glutathione peroxidase activity and serum selenium concentration in atopic asthmatic patients. Clin Exp Allergy 1996;26:838-47.

11 Hu G, Cassano PA. Antioxidant nutrients and pulmonary function: the Third National Health and Nutrition Examination Survey (NHANES III). Am J Epidemiol 2000;151:975-81.

12 Soutar A, Seaton A, Brown K. Bronchial reactivity and dietary antioxidants. Thorax 1997;52:166-70.

13 Shaheen SO, Sterne JA, Thompson RL, et al. Dietary antioxidants and asthma in adults: population-based case-control study. Am J Respir Crit Care Med 2001;164:1823-8.

14 Allam MF, Lucane RA. Selenium supplementation for asthma. Cochrane Database of Systematic Reviews 2004;(2):CD003538.

15 Hasselmark L, Malmgren R, Zetterstrom O, et al. Selenium supplementation in intrinsic asthma. Allergy 1993:48:30-6.

16 American Thoracic Society. Standardization of spirometry, 1994 update. Am J Respir Crit Care Med 1995;152:1107-36.

17 Falaschetti $E$, Laiho J, Primatesta $\mathrm{P}$, et al. Prediction equations for normal and low lung function from the Health Survey for England. Eur Respir J 2004;23:456-63.

18 Marks GB, Burney PG, Premaratne UN, et al. Asthma in Greenwich, UK: impact of the disease and current management practices. Eur Respir J 1997;10:1224-9.

19 Marks GB, Dunn SM, Woolcock AJ. A scale for the measurement of quality of life in adults with asthma. J Clin Epidemiol 1992;45:461-72.

20 Marks GB, Dunn SM, Woolcock AJ. An evaluation of an asthma quality of life questionnaire as a measure of change in adults with asthma. J Clin Epidemiol 1993:46:1103-11.

21 Abdulwadud O, Abramson M, Forbes $A$, et al. Evaluation of a randomised controlled trial of adult asthma education in a hospital setting. Thorax 1999;54:493-500.

22 Pauwels RA, Lofdahl CG, Postma DS, et al. Effect of inhaled formoterol and budesonide on exacerbations of asthma. Formoterol and Corticosteroids Establishing Therapy (FACET) International Study Group. N Engl J Med 1997;337:1405-11

23 Litonjua AA, Sparrow D, Weiss ST. The $\mathrm{FEF}_{25-75} / \mathrm{FVC}$ ratio is associated with methacholine airway responsiveness. The Normative Aging Study. Am J Respir Crit Care Med 1999;159:1574-9.

24 Reddel HK, Jenkins CR, Marks GB, et al. Optimal asthma control, starting with high doses of inhaled budesonide. Eur Respir J 2000;16:226-35.
25 Bousquet J, D'Urzo A, Hebert J, et al. Comparison of the efficacy and safety of mometasone furoate dry powder inhaler to budesonide Turbuhaler. Eur Respir J 2000;16:808-16.

26 Levander OA. Clinical consequences of low selenium intake and its relationship to vitamin E. Ann NY Acad Sci 1982:393:70-82.

27 Tomlinson JEM, MCMahon AD, Chaudhuri R, et al. Efficacy of low and high dose inhaled corticosteroid in smokers versus non-smokers with mild asthma. Thorax 2005;60:282-7.

28 Juniper EF, Price DB, Stampone PA, et al. Clinically important improvements in asthma-specific quality of life, but no difference in conventional clinical indexes in patients changed from conventional beclomethasone dipropionate to approximately half the dose of extrafine beclomethasone dipropionate. Chest 2002; 121:1824-32.

29 Burk RF, Norsworthy BK, Hill KE, et al. Effects of chemical form of selenium on plasma biomarkers in a high-dose human supplementation trial. Cancer Epidemiol Biomarkers Prevent 2006;15:804-10.

30 Rayman MP. The use of high-selenium yeast to raise selenium status: how does it measure up? Br J Nutr 2004;92:557-73.

31 Joint Food Safety and Standards Group. Dietary intake of selenium, Food Surveillance Information Sheet No 126. London: Joint Food Safety and Standards Group, UK Ministry of Agriculture Fisheries and Food, 1997.

32 Joint Food Safety and Standards Group. Total diet study - aluminium, arsenic, cadmium, chromium, copper, lead, mercury, nickel, selenium, tin and zinc, Food Surveillance Information Sheet No 191, 1997. London: Joint Food Safety and Standards Group, UK Ministry of Agriculture Fisheries and Food, 1999.

33 Barclay MNI, MacPherson A, Dixon J. Selenium content of a range of UK foods. J Food Comp Anal 1995;8:307-18.

34 Rayman $M$, Thompson A, Warren-Perry $M$, et al. Impact of selenium on mood and quality of life: a randomized, controlled trial. Biol Psychiatry 2006:59: 147-54

35 Pearson PJ, Lewis SA, Britton J, et al. Vitamin E supplements in asthma: a paralle group randomised placebo controlled trial. Thorax 2004;59:652-6.

36 Fogarty A, Lewis SA, Scrivener SL, et al. Oral magnesium and vitamin C supplements in asthma: a parallel group randomized placebo-controlled trial. Clin Exp Allergy 2003;33:1355-9.

37 Lawlor DA, Davey SG, Kundu D, et al. Those confounded vitamins: what can we learn from the differences between observational versus randomised trial evidence? Lancet 2004;363:1724-7.

38 Shaw R, Woodman K, Crane J, et al. Risk factors for asthma symptoms in Kawerau children. NZ Med J 1994;107:387-91.

39 Devereux G, Seaton A. Diet as a risk factor for atopy and asthma. J Allergy Clin Immunol 2005;115:1109-17.

40 Singer MR, Moore LL, Garrahie EJ, et al. The tracking of nutrient intake in young children: the Framingham Children's Study. Am J Public Health 1995;85:1673-7.

41 Bertheke PG, de WW, Kemper HC, et al. Longitudinal trends in and tracking of energy and nutrient intake over 20 years in a Dutch cohort of men and women between 13 and 33 years of age: the Amsterdam Growth and Health longitudinal study. Br J Nutr 2001;85:375-85.

42 Ruston D, Hoare J, Henderson L, et al. The National Diet and Nutrition Survey adults aged 19-64 years. Volume 4: Nutritional status (anthropometry and blood analytes), blood pressure and physical activity. London: HMSO, 2004.

43 Standing Committee on the Scientific Evaluation of Dietary Reference Intakes of the Food and Nutrition Board. Dietary reference intakes for vitamin C, vitamin $E$, selenium, and carotenoids. Washington, DC: National Academy Press, 2000.

44 Duffield AJ, Thomson CD, Hill KE, et al. An estimation of selenium requirements for New Zealanders. Am J Clin Nutr 1999:70:896-903. 